Tropical Journal of Pharmaceutical Research April 2018; 17 (4): 681-686

ISSN: $1596-5996$ (print); 1596-9827 (electronic)

(C) Pharmacotherapy Group, Faculty of Pharmacy, University of Benin, Benin City, 300001 Nigeria.

\title{
Analysis of the early response to chemotherapy in lung cancer using apparent diffusion coefficient single-slice histogram
}

\author{
Jianxing $\mathrm{Xu}^{1}$, Jiangang Zheng ${ }^{2}$, Zhengyang Zhou ${ }^{1}, \mathrm{XiaO}^{\mathrm{Han}}{ }^{3 *}$ \\ ${ }^{1}$ Department of Radiology, Nanjing Drum Tower Hospital Clinical College of Nanjing Medical University, Nanjing 211166, \\ ${ }^{2}$ Department of Radiology, Affiliated Wujin Hospital of Jiangsu University, Changzhou 213000, ${ }^{3}$ Key Laboratory of Human \\ Functional Genomics of Jiangsu Province, Nanjing Medical University, Nanjing 211166, China
}

*For correspondence: Email: hanxjsh@163.com; Tel/Fax: +86-025-86869425

Sent for review: 9 August 2017

Revised accepted: 17 March 2018

\begin{abstract}
Purpose: To evaluate the application of apparent diffusion coefficient (ADC) values derived from diffusion-weighted imaging (DWI) using single-slice histogram analysis to study the chemotherapy responses in lung cancer.

Methods: A total of 22 chemotherapy patients with advanced lung cancer from the Nanjing Drum Tower Hospital (Nanjing, China) were included in the study. We obtained DWI before and during chemotherapy, performed single-slice histogram analysis of ADC values, and assessed responses after 3 months of chemotherapy. Differences in ADC histogram parameters were compared between the responder and non-responder groups.

Results: After therapy, we classified 13 as responders and 9 patients as non-responders. The recorded peak $A D C$ value ( $A D C_{\text {peak }}$ ) and lowest $A D C$ value $\left(A D C_{\text {lowest }}\right)$ did not show any significant difference in baseline $A D C_{\text {lowest }}$ and $A D C_{\text {peak }}$ between responders and non-responders. After chemotherapy, 13 responders had significant increase in $A D C_{\text {lowest }}$ and $A D C_{\text {peak }}$ compared with pre-treatment values $(p<$ 0.001). $A D C_{\text {lowest }}$ significantly increased in 9 non-responders $(p<0.05)$, although $A D C_{\text {peak }}$ did not significantly increase. $A D C_{\text {peak }}$ changes were significantly larger in the responder group than in the nonresponder group $(p=0.024)$. $A D C_{\text {lowest }}$ changes after treatment were larger in the responder group than in the non-responder group, though not significantly.

Conclusion: $A D C$ values derived from single-slice histogram analysis may provide a useful and clinically feasible method for monitoring early chemotherapy response in patients with lung cancer.
\end{abstract}

Keywords: Lung cancer, Chemotherapy, Apparent diffusion coefficient values, Diffusion-weighted imaging, Single-slice histogram analysis

This is an Open Access article that uses a funding model which does not charge readers or their institutions for access and distributed under the terms of the Creative Commons Attribution License (http://creativecommons.org/licenses/by/4.0) and the Budapest Open Access Initiative (http://www.budapestopenaccessinitiative.org/read), which permit unrestricted use, distribution, and reproduction in any medium, provided the original work is properly credited.

Tropical Journal of Pharmaceutical Research is indexed by Science Citation Index (SciSearch), Scopus, International Pharmaceutical Abstract, Chemical Abstracts, Embase, Index Copernicus, EBSCO, African Index Medicus, JournalSeek, Journal Citation Reports/Science Edition, Directory of Open Access Journals (DOAJ), African Journal Online, Bioline International, Open-J-Gate and Pharmacy Abstracts

\section{INTRODUCTION}

Chemotherapy is the dominant treatment strategy for patients with advanced lung cancer.
Response Evaluation Criteria in Solid Tumors (RECIST) is often used as standard for evaluating treatment responses in lung cancer, which analyzes tumor size changes by 
employing computed tomography (CT) [1]. However, because of the relatively slow tumor shrinkage, the first response evaluation is often carried out after two cycles of chemotherapy by CT [2], conventional imaging procedures may not accurately assess the response at the early treatment stage.

In recent years, investigations have reported that diffusion-weighted imaging (DWI) has potential for monitoring the early treatment response in many malignant tumors, including rectal cancer, cervical cancer, breast cancer, head and neck cancers, prostate cancer and brain tumors [3 - 5], and ADC derived from DWI changes as early as $24 \mathrm{~h}$ after therapy [6]. A variety of methods have been applied to measuring mean ADC values on ADC maps from various regions of interest (ROIs) located in the tumor $[7,8]$. Histogram analysis based on the whole-tumor ROI method is preferred for differentiating or grading tumors or predicting treatment response in various organs [9-12]. Single-slice histogram analysis can be used to generate the ADC histogram, which represents the pixel frequency of each ADC value for the slice image. Single-slice histogram analysis requires virtually no data manipulation and can be generated in seconds.

The goal of the present study is to analyze ADC values derived from DWI using single-slice histogram analysis, andalso to investigate the usefulness of ADC values in evaluating the response to chemotherapy in lung cancer.

\section{EXPERIMENTAL}

\section{Subjects}

This study was approved by the Ethical Committee of Nanjing Drum Tower Hospital, Nanjing, China (approval no. EH201501-3), and was performed according to the guidelines of Declaration of Helsinki [13]. All patients were informed about the potential contraindications and benefits associated with DWI and contrastenhanced magnetic resonance imaging (MRI).

Patients in this study were diagnosed with stage IIIB or IV histologically confirmed advanced lung cancer at Nanjing Drum Tower Hospital (Nanjing, China) from Feb. 2015 to Aug. 2016 and met the following inclusion criteria: the largest diameter of the pulmonary mass was $3.0 \mathrm{~cm}$ or larger, no history of previous chemotherapy or radiation therapy, and no contraindication to high-field strength MRI (no claustrophobia and no known metallic implants). Lung cancer in all patients was pathologically confirmed by bronchoscopic biopsy or percutaneous lung biopsy. The histological types of cancer in patients included adenocarcinomas, small cell carcinoma and squamous cell carcinoma. The exclusion criteria included: having contraindication to gadopentetate dimeglumine (allergy or renal dysfunction), undergoing radiotherapy simultaneously with chemotherapy, interruption of treatment in 3 months, and poor visualization of the tumor by MRI. Tumor response after 3 months of therapy was evaluated according to the RECIST criteria ${ }^{2}$, including target and nontarget lesions at CT. Tumor response after therapy was classified as follows: responders when the target lesion disappeared or when the longest diameter of the target lesion decreased by at least $30 \%$ from the pre-therapy size; and non-responders - when the target lesion was not classified as a responder or new lesions appeared [14].

\section{Image acquisition}

Pre-treatment MRIs and post-treatment MRIs were obtained within 1 week prior to the first course of chemotherapy and 2 weeks after the start of the first course of chemotherapy, respectively. MRI was carried out by a 1.5-T unit with a body phased array coil (Avanto, Siemens, Germany). Firstly, breath-hold T2-weighted coronal images and T1- and T2-weighted axial images were obtained. Subsequently, breath-free DWI was obtained in the transverse plane using single-shot, spin-echo echo-planar imaging sequence with $b$ values of 50 and $800 \mathrm{~s} / \mathrm{mm}^{2}$. By using the indicated $b$ values above, ADC maps were obtained from DWI. The total acquisition time for DWI was $50 \mathrm{~s}$. After DWI, the contrastenhanced T1-weighted images were performed in the axial plane following administration of GdDTPA (Magnevist, Germany).

\section{Data analysis}

Generation and analysis of single-slice ADC histogram. A free-standing workstation (UNITED IMAGING Medical Systems) was used and single-slice ADC histograms were obtained by using the FuncTool of the workstation. The single axial slice was selected according to the level of the largest diameter of the tumor. Tumor boundaries were defined in reference to the T2weighted and contrast-enhanced T1-weighted images. The ROls were slightly smaller than actual tumor size to reduce the influence of partial volume effect. The peak ADC value $\left(A D C_{\text {peak }}\right)$ and lowest $A D C$ value $\left(A D C_{\text {lowest }}\right)$ of the histograms were recorded. The peak value for each case was recorded as the $A D C_{\text {peak }}$ and the left leading edge of the histogram (where the 
voxel frequency was approximately 5 pixels) was recorded as the $\mathrm{ADC}_{\text {lowest }}$.

\section{Statistical analysis}

SPSS software version 13.0 (SPSS Inc., Chicago, IL, USA) was used for data analysis. Paired t-tests were used to compare differences between pre- and post-treatment MRI parameters in the same patient. Independent samples t-tests were performed to compare the differences between responders and nonresponders groups. $p<0.05$ was considered as statistically significant.

\section{RESULTS}

Among 25 patients, the DWI of 22 (88\%) was graded as good or moderate. The DWI of the other three patients (12\%) was graded as poor and they were excluded from this study. All 22 patients with qualified baseline DWI received chemotherapy. Response assessment after 3 months of therapy was successfully performed. As a result, 13 and 9 patients were classified after therapy as responders and non-responders, respectively.

Single-slice ADC histograms were generated and $A D C_{\text {peak }}$ and $A D C_{\text {lowest }}$ were recorded from pretreatment and post-treatment ADC maps. Results and comparisons of $\mathrm{ADC}_{\text {lowest }}$ and $A D C_{\text {peak }}$ are shown in Table 1 and Table 2.

Table 1: Lowest $A D C$ values before and after chemotherapy

\begin{tabular}{lccccc}
\hline Variable & $\mathbf{N}$ & $\begin{array}{c}\text { Pre- } \\
\text { ADC }\end{array}$ & $\begin{array}{c}\text { Powest- } \\
\text { ADC lowest }\end{array}$ & Change & $\begin{array}{c}\text { P- } \\
\text { value }\end{array}$ \\
\hline Responders & 13 & $0.509 \pm$ & $0.726 \pm$ & $0.216 \pm$ & 0.001 \\
Non- & & 0.147 & 0.181 & 0.256 & 0.001 \\
responders & 9 & $0.525 \pm$ & $0.650 \pm$ & $0.125 \pm$ & 0.027 \\
\hline
\end{tabular}

Values listed are the mean \pm standard deviations; units, $\times 10^{-3} \mathrm{~mm}^{2} / \mathrm{s}$.

Table 2: Peak $A D C$ values before and after chemotherapy

\begin{tabular}{lccccc}
\hline Variable & N & $\begin{array}{c}\text { Pre- } \\
\text { ADC }_{\text {peak }}\end{array}$ & $\begin{array}{c}\text { Post- } \\
\text { ADC }_{\text {peak }}\end{array}$ & Change & $\begin{array}{c}\boldsymbol{P} \text { - } \\
\text { value }\end{array}$ \\
\hline Responders & 13 & $1.068 \pm$ & $1.656 \pm$ & $0.588 \pm$ & 0.001 \\
& & 0.248 & 0.544 & 0.409 & \\
Non- & 9 & $1.014 \pm$ & $1.216 \pm$ & $0.202 \pm$ & 0.065 \\
responders & & 0.228 & 0.320 & 0.283 & \\
\hline
\end{tabular}

Values listed are the mean \pm standard deviations; units $\times 10^{-3} \mathrm{~mm}^{2} / \mathrm{s}$

No significant difference was observed in pretreatment $A D C_{\text {lowest }}$ and $A D C_{\text {peak }}$ between responders and non-responders $(p=0.855$ and $p$ $=0.606$, respectively).
After chemotherapy, 13 responders had significant increases in $A D C_{\text {lowest }}$ and $A D C_{\text {peak }}$ compared with pre-treatment value $(p<0.001)$. Nine non-responders had a significant increase in $\operatorname{ADC}_{\text {lowest }}(p<0.05)$, while there was no significant increase in $\operatorname{ADC}_{\text {peak }}(p>0.05)$. Changes in $A D C_{\text {peak }}$ were more significant in the responder group than in the non-responder group ( $p=0.024)$. Although no statistically changes in $A D C_{\text {lowest }}$ were larger in the responder group than that in non-responder group $(p=0.178)$.

\section{DISCUSSION}

Histogram analysis is usually used to analyze pixel numbers with the same signal intensity in an ROI, evaluate the distributions of tumor signal intensity, and describe the heterogeneity of the tumor. In particular, histogram analysis for the whole tumor can reduce the arbitrariness that can occur with drawing ROls. Hence, ADC histogram analysis has been considered to be a more reproducible method to determine tumor heterogeneity, which is significant because heterogeneity is associated with poorer prognosis $[15,16]$.

The tumor heterogeneity change can be analyzed intuitively by histogram and quantitatively by descriptive parameters of the histogram [17]. However, the major problem in ROI drawing for the whole lesion may be the irregular shape of lung cancer. Histogram analysis of the whole lung cancer lesionis laborintensive and requires professional software that is not commonly available in a clinic. The United Imaging FuncTool can rapidly analyze the singleslice ADC map to produce a histographic display of voxel occurrence frequency as a function of $A D C$ value, e.g., $A D C_{\text {peak }}, A D C_{\text {lowest }}$ and the overall shape of the ADC histogram [18].

In this study, the changes in $A D C_{\text {peak }}$ were more significant in the responder group than in the non-responder group, which had been previously reported for other tumors [9]. $A D C_{\text {peak }}$ indicates that a larger proportion of the tumor, has the highest frequency, and tissues with high ADC values account for a significant part of the whole lesion. We speculated that if this part of the tumor greatly changed during the treatment, so would the value of the peak. Thus, $A D C_{\text {peak }}$ may be a promising parameter to assess early treatment responses in lung cancer.

The results demonstrated that $A D C_{\text {lowest }}$ of the tumor increased after treatment, both in the responder group and non-responder group, and 
that the changes in the responder group were larger, although not significant than in the nonresponder group. This result was not consistent with the results of previous research. Previous findings demonstrated that low percentile ADC values taken from the left leading edge of the tumor histogram increased more after treatment in the responder group than in the non-responder group [26]. We speculate that this was because the $A D C_{\text {lowest }}$ was not stable and the number of pixels of $A D C_{\text {lowest }}$ from the histogram was relatively small. Additionally, this value may be easily affected by noise, artifacts, and adjacent structures, which are difficult to avoid. In addition, some ROls encompassed cavities found in the tumor or occurring after the biopsy, which would also affect the results (Figure 1).

Besides various ADC values, the shape of the ADC histogram also indicated the character of the tissue structure. In addition, by using histogram analysis in pre- and post-treatment, the histogram could show changes in tumor heterogeneity. The histogram of the responder group shifted obviously to the right side (Figure 2), indicating a larger proportion of tumors with a higher ADC value after treatment than prechemotherapy. However, the histogram graph did not shift significantly to the right side in the non-responder group (Figure 3). In responder group, tumor cell necrosis resulted in increased ADC after therapy. This result is consistent with reports of other tumors in the literature $[19,20]$. The findings suggest that single-slice ADC histogram analysis is a rapid and clinically useful technique to monitor the early tumor response and predict the effectiveness of lung cancer therapy.

The present study has some limitations. There were few patients were enrolled in this study. In future studies, the inclusion of more patients will help determine and validate the proper cutoff value for detecting responders in single-slice ADC histogram analysis. We used $b$ values of 50 and 800 in the diffusion MRI protocol, but other $b$ values were not used. Thus, the best $b$ value for lung imaging was not determined. It will be necessary to use other $b$ values for DWI to evaluate the effectiveness of the therapy.
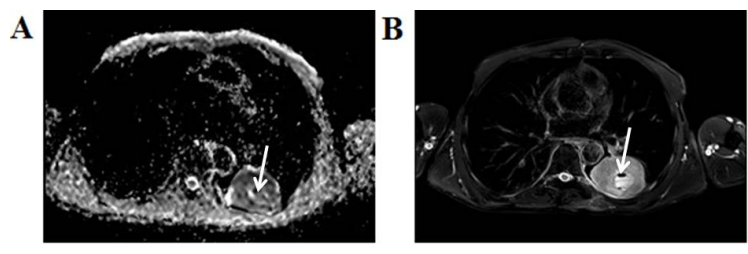

Figure 1: Male patient, 66 years old, squamous cell carcinomas. ADC map $(A)$ and T2-weighted axial image (B) showed cavitation (white arrow) in the tumor after biopsy.
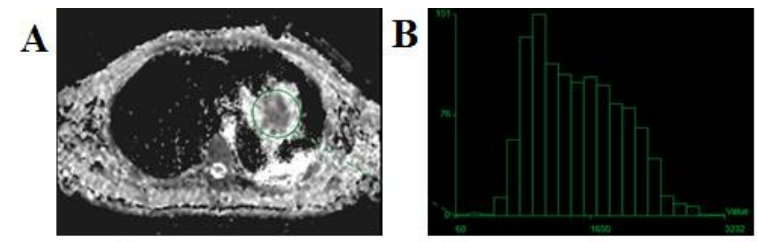

C
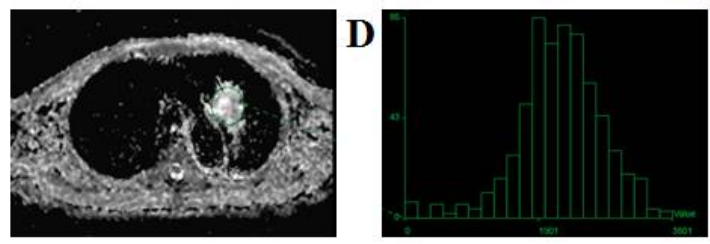

$\mathbf{E}$

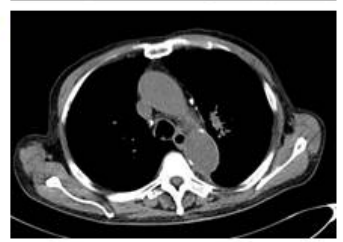

Figure 2: Male patient, 76 years old, small cell carcinoma. Change in histogram between pre- and post-treatment chemotherapy in responder patient. $A D C$ map $(A, C)$ and single-slice histogram (B, D) show $A D C$ value displayed on the $x$-axis with $A D C$ in $\mathrm{cm}^{2} / \mathrm{s} \times 10^{-2}$; the number of pixels is displayed on the $y$-axis. The histogram graph shifts visibly to the right side after two weeks of therapy. After 3 months of therapy, the largest diameter of target lesions decreased by at least $90 \%(\mathrm{E})$

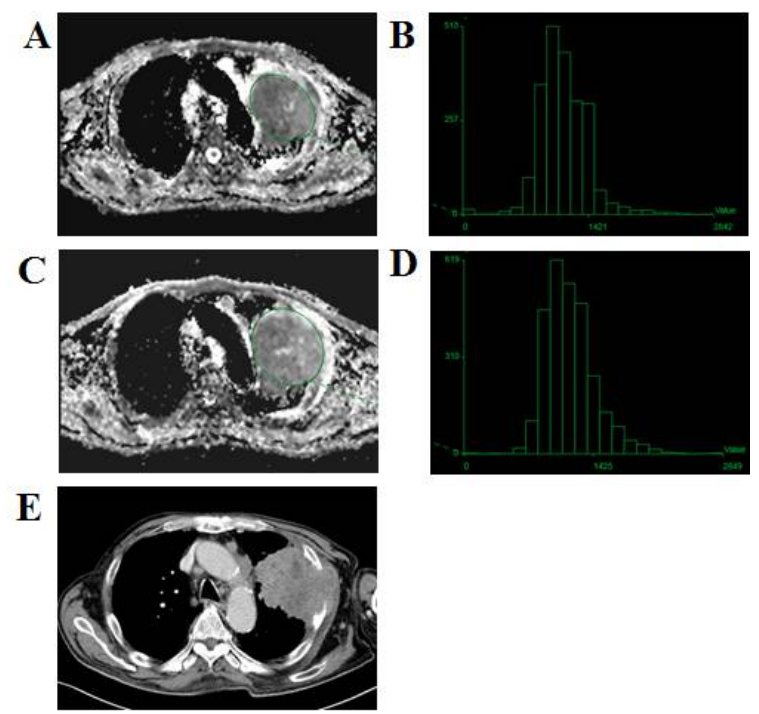

Figure 3: Male patient, 69 years old, squamous cell carcinomas. Change in histogram between pre- and post-treatment chemotherapy in non-responder patients. ADC map ( $A, C)$ and single-slice histogram $(B, D)$ show the $A D C$ value displayed on the $x$-axis with $A D C$ in $\mathrm{cm}^{2} / \mathrm{s} \times 10^{-2}$; the number of pixels is displayed on the $y$-axis. The histogram graph does not shift significantly to the right side after 2 weeks of therapy. After 3 months of therapy, there was approximately a $10 \%$ increase in the largest diameter of target lesion (E) 


\section{CONCLUSION}

$A D C$ values obtained from single-slice histogram analysis of lung cancer may provide a useful tool for monitoring early tumor response and evaluating the effectiveness of a therapy. If this method is successfully used in practice, physicians would be able to reliably predict the early response to chemotherapy for lung cancer. Once the candidate drugs have been shown to be ineffective, patients could immediately try different anticancer drugs. This method will avoid situations where the toxic effects of anticancer drugs are tolerated without any corresponding clinical benefit.

\section{DECLARATIONS}

\section{Conflict of Interest}

No conflict of interest associated with this work.

\section{Contribution of Authors}

The authors declare that this work was done by the authors named in this article and all liabilities pertaining to claims relating to the content of this article will be borne by them. In addition, Xiao Han conceived and designed the study, Zhengyang Zhou collected and analyzed the data, Jianxing $\mathrm{Xu}$ and Jiangang Zheng wrote the manuscript. All authors have read and approved the manuscript for publication.

\section{REFERENCES}

1. Therasse P, Arbuck SG, Eisenhauer EA, Wanders J, Kaplan RS, Rubinstein L, Verweij J, Van Glabbeke M, van Oosterom AT, Christian MC, et al. New Guidelines to Evaluate the Response to Treatment in Solid Tumors. $J$ Natl Cancer Inst 2000; 92(3): 205-216.

2. de Geus-Oei LF, van der Heijden HF, Visser EP, Hermsen $R$, van Hoorn BA, Timmer-Bonte JN, Willemsen AT, Pruim J, Corstens FH, Krabbe PF, et al. Chemotherapy Response Evaluation with 18F-FDG PET in Patients with Non-Small Cell Lung Cancer. J Nucl Med 2007; 48(10): 1592-1598.

3. Chenevert TL, McKeever PE, Ross BD. Monitoring early response of experimental brain tumors to therapy using diffusion magnetic resonance imaging. Clin Cancer Res 1997; 3(9): 1457-1466.

4. Jennings $D$, Hatton $B N$, Guo J, Galons JP, Trouard TP, Raghunand N, Marshall J, Gillies RJ. Early Response of Prostate Carcinoma Xenografts to Docetaxel Chemotherapy Monitored With Diffusion MRI. Neoplasia 2002; 4(3): 255-262.

5. Hein PA, Kremser $C$, Judmaier W, Griebel J, Pfeiffer KP, Kreczy A, Hug EB, Lukas P, DeVries AF. Diffusion- weighted magnetic resonance imaging for monitoring diffusion changes in rectal carcinoma during combined, preoperative chemoradiation: preliminary results of a prospective study. Eur J Radiol 2003; 45(3): 214-222.

6. Wang $\mathrm{H}$, Fei B. Diffusion-weighted MRI for monitoring tumor response to photodynamic therapy. J Magn Reson Imaging 2010; 32(2): 409-417.

7. Herneth AM, Guccione S, Bednarski M. Apparent Diffusion Coefficient: a quantitative parameter for in vivo tumor characterization. Eur J Radiol 2003; 45(3): 208213.

8. Thoeny HC, Ross BD. Predicting and monitoring cancer treatment response with diffusion-weighted MRI. J Magn Reson Imaging 2010; 32(1): 2-16.

9. Cho SH, Kim GC, Jang YJ, Ryeom H, Kim HJ, Shin KM, Park JS, Choi GS, Kim SH. Locally advanced rectal cancer: post-chemoradiotherapy ADC histogram analysis for predicting a complete response. Acta Radiol 2015; 56(9): 1042-1050.

10. Ahn SJ, Choi SH, Kim YJ, Kim KG, Sohn CH, Han MH, Chang KH, Min HS. Histogram Analysis of Apparent Diffusion Coefficient Map of Standard and High B-value Diffusion MR Imaging in Head and Neck Squamous Cell Carcinoma: A Correlation Study with Histological Grade. Acad Radiol 2012; 19(10): 1233-1240.

11. Lee J, Choi SH, Kim JH, Sohn CH, Lee S, Jeong J. Glioma grading using apparent diffusion coefficient map: application of histogram analysis based on automatic segmentation. NMR Biomed 2014; 27(9): 1046-1052.

12. Suo ST, Chen XX, Fan $Y, W u L M$, Yao QY, Cao MQ, Liu $Q, X u J R$. Histogram Analysis of Apparent Diffusion Coefficient at $3.0 T$ in Urinary Bladder Lesions: Correlation with Pathologic Findings. Acad Radiol 2014; 21(8): 1027-1034.

13. Helsinki Do. The 59th World Medical Association. 2008.

14. Chang $Q, W u N$, Ouyang H, Huang Y. Diffusion-weighted magnetic resonance imaging of lung cancer at 3.0 T: a preliminary study on monitoring diffusion changes during chemoradiation therapy. Clin Imaging 2012; 36(2): 98103.

15. Aziz MU. Monitoring brain development with quantitative diffusion tensor imaging. Dev Sci 2002; 5(3): 286-292.

16. Zhang L, Thomas KM, Davidson MC, Casey BJ, Heier $L A$, Uluğ $A M$. MR quantitation of volume and diffusion changes in the developing brain. AJNR Am J Neuroradiol 2005; 26(1): 45-49.

17. Choi MH, Oh SN, Rha SE, Choi Jl, Lee SH, Jang HS, Kim JG, Grimm R, Son Y. Diffusion-weighted imaging: Apparent diffusion coefficient histogram analysis for detecting pathologic complete response to chemoradiotherapy in locally advanced rectal cancer. J Magn Reson Imaging 2016; 44(1): 212-220.

18. Keith AC, Christopher GF. Apparent diffusion coefficient histogram analysis of neonatal hypoxic-ischemic encephalopathy. Pediatr Radiol 2014; 44(6): 738-746.

19. Kyriazi S, Collins DJ, Messiou C, Pennert K, Davidson RL, Giles SL, Kaye SB, Desouza NM. Metastatic Ovarian and Primary Peritoneal Cancer: Assessing 
Chemotherapy Response with Diffusion-weighted MR Imaging-alue of Histogram Analysis of Apparent Diffusion Coefficients. Radiol 2011; 261(1): 182-192.

20. King $A D$, Chow $K K, Y u K H$, Mo $F K$, Yeung $D K$, Yuan J, Bhatia KS, Vlantis AC, Ahuja AT. Head and Neck
Squamous Cell Carcinoma: Diagnostic Performance of Diffusion-weighted MR Imaging for the Prediction of Treatment Response. Radiol 2013; 266(2): 531-538. 